\title{
Slight hypodensities \\ of the subcortical white matter
}

We present the case of a 43-year-old woman with history of unmedicated dyslipidemia, non-functioning thyroid nodules and arterial hypertension diagnosed for 5 years and controlled with angiotensin converting inhibitor therapy. She was admitted at the Emergency Department due to frontal headache lasting for 15 days associated with episodes of blurred vision with a few minutes of duration and vomiting in the previous day. The physical examination revealed high blood pressure $(217 / 101 \mathrm{mmHg})$, with no other remarkable alterations. The electrocardiogram showed no acute changes; the analytical study revealed normal blood count, ionogram, renal function and liver profile and type 2 urine without proteinuria. Computed tomography (CT) of the brain showed slight hypodensities of the subcortical white matter, frontal and mainly parietal (Figure 1), and the hypothesis of Posterior Reversible Encephalopathy Syndrome (PRES) was considered. Cerebral Magnetic Resonance imaging (MRI) revealed numerous areas of hyperintensity, observed in sequences with long repetition time, with confluent pattern, mainly subcortical in frontoparietal regions of non-specific gliotic nature (Figure 2). The patient was hospitalized, under antihypertensive therapy, with improvement of the tension profile and resolution of the symptomatology. The etiological study excluded other causes for brain injuries, injury to other target organs and causes of secondary hypertension. The diagnosis of PRES was established.

PRES was first codified as a single named syndrome in a 1996 case series $^{1}$. PRES is a clinical imagiological syndrome, whose overall incidence is unknown and is more common in women ${ }^{1}$. The pathogenesis remains unclear, but appears to be related to disordered cerebral autoregulation and endothelial dysfunction ${ }^{1}$. A wide variety of medical conditions have been implicated as causes of PRES. The first association described was with arterial hypertension, reported in about $75 \%$ of the cases ${ }^{2}$ and other conditions include autoimmune diseases and therapy with immunosuppressive drugs ${ }^{2}$. In the appropriate clinical setting, clinicians should recognize the neurologic syndrome, characterized by headache, altered consciousness, visual disturbances and seizures ${ }^{3}$, and order a brain MRl; the most commonly observed abnormalities are punctate or confluent areas of increased signal on proton density and T2-weighted images ${ }^{4}$, as in the case described. Treatment includes supportive measures and correction of the underlying condition (such as tension control). In many cases, PRES seems to be fully reversible after removal of the inciting factor ${ }^{1}$. However, in the most severe cases there is a risk of permanent neurologic disability or death ${ }^{5}$. Early recognition and intervention are critical in prognosis.

Keywords: Posterior reversible encephalopathy syndrome, magnetic resonance, hypertension.

\section{References}

1. Hinchey J, Chaves C, Appignani B, Breen J, Pao L, Wang A, et al. A reversible posterior leukoencephalopathy syndrome. N Engl J Med. 1996;334(8):494-500.

2. Bartynski WS. Posterior reversible encephalopathy syndrome, part 1: fundamental imaging and clinical features. AJNR Am J Neuroradiol. 2008;29(6):1036-42.

3. Fugate JE, Claassen DO, Cloft HJ, Kallmes DF, Kozak OS, Rabinstein AA. Posterior reversible encephalopathy syndrome: associated clinical and radiologic findings. Mayo Clin Proc. 2010;85(5):427-32.

4. Lamy C, Oppenheim C, Méder JF, Mas JL. Neuroimaging in posterior reversible encephalopathy syndrome. J Neuroimaging. 2004;14(2):89-96.

5. Covarrubias DJ, Luetmer PH, Campeau NG. Posterior reversible encephalopathy syndrome: prognostic utility of quantitative diffusion-weighted MR images. AJNR Am J Neuroradiol. 2002;23(6):1038-48.
Figure 1. Computed tomography of the brain showed slight hypodensities of the frontal and parietal subcortical white matter.

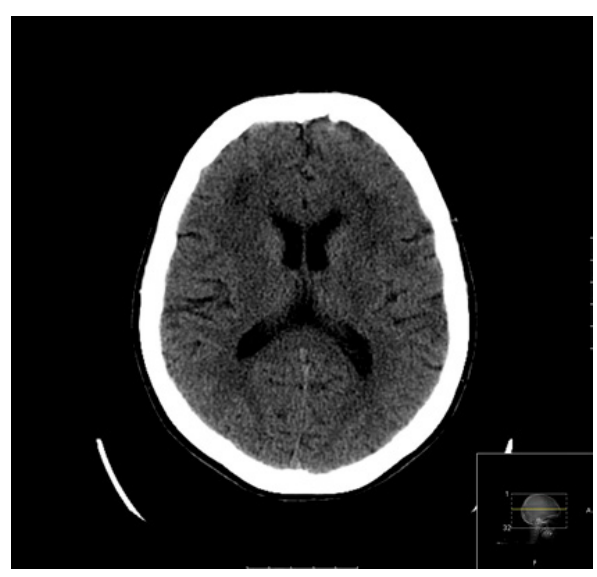

Figure 2. Cerebral Magnetic Resonance imaging (sequences with long repetition time) showed numerous areas of hyperintensity with confluent pattern, mainly subcortical in frontoparietal regions.

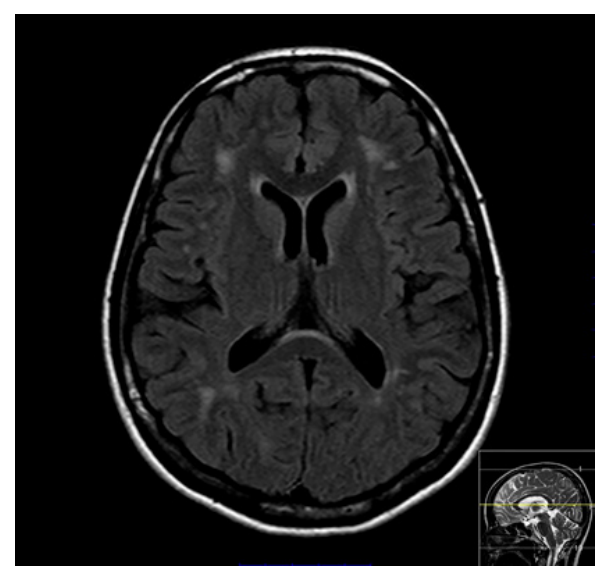

Diagnosis: Posterior reversible encephalopathy syndrome: a clinical radiographic syndrome

\author{
Ana Raquel Freitas, Heloísa Ribeiro \\ Centro Hospitalar de Entre o Douro e Vouga, \\ Santa Maria da Feira, Portugal \\ Correspondencia: rakel.freitas@hotmail.com \\ Cómo citar este artículo: Freitas AR, Ribeiro $\mathrm{H}$ \\ Posterior reversible encephalopathy syndrome: \\ a clinical radiographic syndrome. Galicia Clin 2018; 79 (4): 144 \\ Recibido: 01/11/2017; Aceptado: 27/11/2017
}

